\title{
Fear, Anger, and Media-Induced Trauma During the Outbreak of COVID-19 in the Czech Republic
}

\author{
Radek Trnka ${ }^{1,2}$, Radmila Lorencova ${ }^{3}$ \\ ${ }^{1}$ Prague College of Psychosocial Studies, Czech Republic \\ 2 OUSHI, Palacky University Olomouc, Czech Republic \\ ${ }^{3}$ College of Applied Psychology, Terezin, Czech Republic
}

\begin{abstract}
Fear, anger and hopelessness were the most frequent traumatic emotional responses in the general public during the first stage of outbreak of the COVID-19 epidemic in the Czech Republic $(N=1,000)$. The four most frequent categories of fear were determined: (a) fear of the negative impact on household finances, (b) fear of the negative impact on the household finances of significant others, (c) fear of the unavailability of health care, and (d) fear of an insufficient food supply. The pessimistic communications used by the Czech mass media contributed to intensifying traumatic feelings, fears and psychological distress in the general public during the outbreak of the COVID-19 epidemic.
\end{abstract}

(C) 2020, American Psychological Association. This paper is not the copy of record and may not exactly replicate the final, authoritative version of the article. Please do not copy without authors' permission. The final article is available via its DOI: 10.1037/tra0000675

Keywords: COVID-19, Virus, Pandemic, Epidemic, Outbreak, Coronavirus SARSCoV-2, Trauma, Psychological Trauma, Mass Trauma, Mass Traumatic Events, Psychological Traumatization, Traumatic Stress, Traumatic Feelings, Emotional Reactions to Traumatic Events, Fear, Anger, Hopelessness, Depression, Anxiety, Anxious, Psychological Distress, Coping with Stress, Isolation, Mental Health, WellBeing, Existential Concerns, Mass Media, Public Communication, Media Communication, Journalist, Media Officials, Decision Making, Public Health, Decision Makers, Restrictions, Interventions, Measures, General Public, Traumatized Public, Health Care, Government, Optimism, Pessimism, Optimistic, Pessimistic, Unprecedented Crises

MeSH Headings: Emotions, Fear, Anger, Stress, Stress Reaction, Stress Response, Stress Reactivity, Defense Mechanisms, Affect, Feelings

The present report provides basic information about distress and traumatic responses accompanying the first seven weeks of the outbreak of the COVID-19 epidemic in the Czech Republic (see also Cao et al., 2020; Kisely et al., 2020; Lei et al., 2020; Liang et al., 2020; Röhr et al., 2020; Usher, Durkin, \& Bhullar, 2020; Wang et al., 2020; Zhou et al., 2020). The Czech situation is unique because of the relatively quick reactions of decision-makers, who imposed severe restrictions immediately during the first two weeks of the epidemic. After March 1, 2020, when the first three 
patients were positively diagnosed with COVID-19, strict measures were imposed: a prohibition on visits to social facilities and hospitals (March 9); the total closure of the national borders (March 13); the closing of all shops, with the exceptions of food and other indispensable items (March 14); areal curfews, with the exception of ways from home to work and back (March 16); and the obligation of everyone to wear surgical or homemade masks covering the mouth and nose (March 19). Despite the objections expressed even by some epidemiologists regarding the strictness of these measures, the reproduction number $(R 0)$ fell below 1.5 after March 29 and reached 1 by April 8 , 2020 (Seznam.cz, 2020). At the end of March, 2020, the decrease of $R 0$ was also accompanied by a partial decrease of fear and pessimism in the general public (Figure 1; see also Ahorsu et al., 2020; Harper, Satchell, Fido, \& Latzman, 2020; Soraci et al., 2020).

Several insights regarding psychological trauma, emotional responses, and distress in the Czech population are already available from the first public surveys (for an overview of the impacts on global mental health, see, e.g., Torales, O'Higgins, Castaldelli-Maia, \& Ventriglio, 2020). A public representative survey of discrete emotional reactions related to the COVID-19 epidemic was conducted on March 1920, 2020 (Behavio Labs, 2020). Participants ( $N=1,000 ; 490$ males and 510 females) were asked which emotions they felt at the time of the COVID-19 epidemic. Participants could indicate more than one option. A total of 370 participants $(37 \% ; 33 \%$ males and $67 \%$ females) indicated fear, 160 participants (16\%; 58\% males and $42 \%$ females) indicated anger, and 50 participants (5\%; 31\% males and $69 \%$ females) indicated hopelessness. Interestingly, a large proportion of the population, 390 participants in all, did not show any substantial psychological trauma and reported that they felt relatively fine (60\% males and $40 \%$ females), and 260 participants reported that they felt the challenge (57\% males and $43 \%$ females; Figure 2$)$. The data showed that fear was the most frequent emotional response among females $(n=249 ; 49 \%)$, while "I feel fine" was the most frequent response among males ( $n=235 ; 48 \%)$.

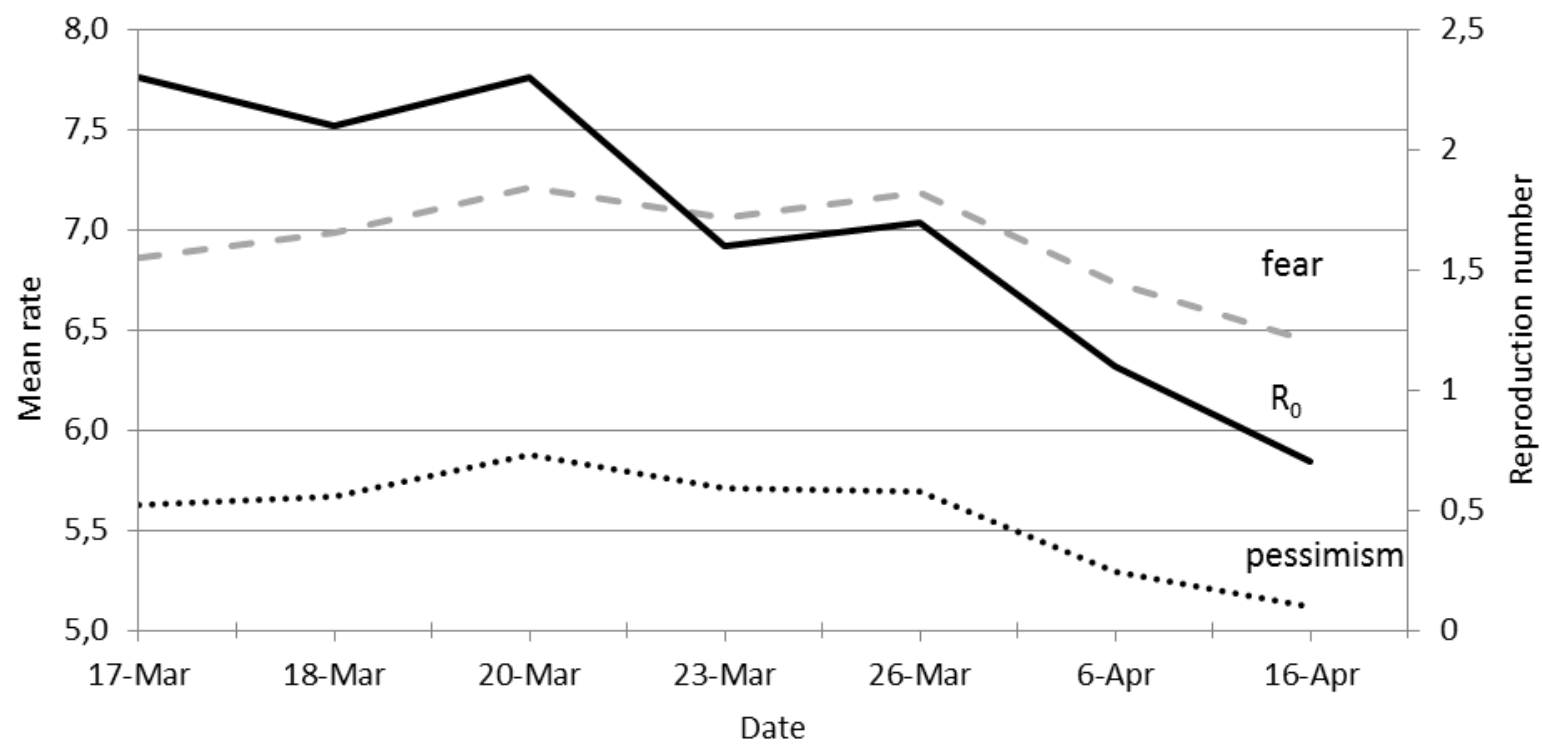

Figure 1 Development of the fear and pessimism in the general public (Source: European National Panels and Seznam.cz) 
Another survey focused on fear and optimism/pessimism in five European countries (European National Panels, 2020). The reactions of Czechs ranked highest in the rate of optimism relating to combatting the pandemic in comparison to Slovakia, Bulgaria, Hungary, and Poland. A representative sample of 3,200 participants aged $15+$ participated in the Czech survey. An index of optimism/pessimism (see Figure 1) was constructed from the participants' responses to three questions, such as "How do you think the COVID-19 disease situation caused by the new type of coronavirus SARS-CoV-2 will develop?" rated on a $0-10$ rating scale $(0=I$ am very pessimistic, 10 $=I$ am very optimistic). In the same survey, fear of COVID-19 was measured on the same sample. An index of fear (see Figure 1) was constructed from the participants' responses to three questions, such as "How concerned are you about the health effects of COVID-19 disease caused by the new type of coronavirus SARS-CoV-2 on you personally?" rated on a $0-10$ rating scale $(0=$ not concerned at all, $10=$ very concerned). Both surveys were repeated seven times to monitor development over time (see Figure 1). Furthermore, the main sources of fear were surveyed on April 26, $2020(N=3,200$; European National Panels, 2020). Participants rated individual sources of fear on a $0-10$ rating scale. The most-rated source of fear was represented by a fear of price increases (mean rate $=7.65$ ), followed by a fear of falling earnings ( mean rate $=5.74)$, someone close losing a job (mean rate $=5.72)$, the unavailability of health care (mean rate $=5.34$; see also health anxiety in Asmundson \& Taylor, 2020 ), the loss of one's own job (mean rate $=4.49$ ), and the fear of an insufficient food supply (mean rate $=3.95$; European National Panels, 2020).

In another survey (STEM, 2020) conducted between April 23 and 25, 2020, a total of 626 participants $(62 \%)$ of a representative sample $(N=1,008)$ stated that they are coping with the restrictions "relatively without problems," 336 participants (33.3\%) are coping "with smaller problems," 38 participants (3.8\%) are coping "with big problems," and 8 participants $(0.8 \%)$ are coping "with very big problems."

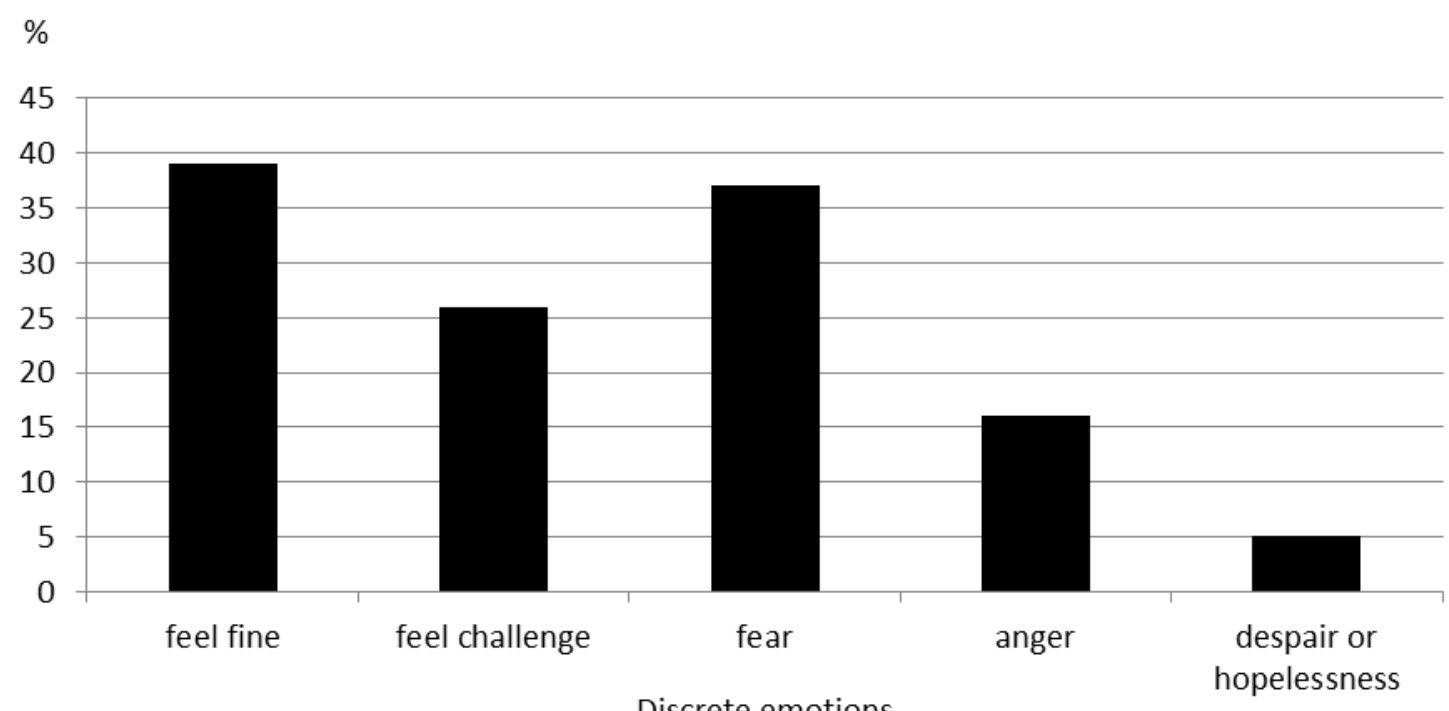

Figure 2 Discrete emotional responses related to the COVID-19 epidemic in the Czech Republic (Source: Behavio Labs) 


\section{Helpful and Unhelpful Factors Impacting Mental Health}

At the beginning of March, 2020, stressful information presented in the media created an unjustifiably pessimistic picture of the COVID-19 outbreak and contributed to the psychological traumatization of the Czech population, especially among older adults. Older adults were the most affected part of the population because of their isolation and their very limited opportunity to share their worries and emotions with others. In an effort to reach a broader audience, the Czech mass media published hundreds of articles involving stories of patients from the nonvulnerable part of the world population who were infected by COVID-19 and had died or had rare or extremely uncommon serious health outcomes. Most of these media messages were presented in a highly emotional manner, which contributed to intensifying traumatic feelings, fears, anxieties, and distress during the first weeks of the COVID-19 outbreak (see also Dong \& Zheng, 2020).

In reaction to this situation, the chairman of the Czech Senior Council negotiated several supportive activities with the Czech government, namely home delivery for older adults, special shopping hours for older adults in supermarkets, the establishing of help lines, and also the launching of a new TV channel with an anti-stress broadcast targeted to older viewers. At the same time, many civic activities were started, for example, an initiative called "Scientists Against Melancholy," in which Czech scientists posted short supportive messages to the general public on an online social network.

Interestingly, strong collective feelings of solidarity accompanied the subsequent weeks of the COVID-19 outbreak in Czech society. People began to behave very thoughtfully toward each other. Because there was a lack of surgical masks on the market, many people started to make facemasks themselves. Moreover, people who were able to produce homemade masks provided them to those who could not make them on their own.

\section{The Organization of Health Care}

In anticipation of an explosive increase in the number of people infected by COVID-19, several hospitals modified selected departments to become specialized for care of patients suffering from COVID-19. Importantly, the health care service faced a problem with a lack of surgical masks and hygiene material. Several supplies of this material were arranged by the government. Also, many private and civic organizations spontaneously joined and offered their help to finance or support public health care because of the COVID-19 outbreak. A very influential nongovernmental project even developed a plan for quick local production of lung ventilators for a hypothetical future lack of such ventilation units (https://covidhacks.org/). This project immediately acquired public support and collected 370,000 EUR in one day through a public Internet fund-raising campaign. In the subsequent weeks, a functional prototype was developed and the technology is now waiting for certification.

Health care for anxiety, depression, and posttraumatic stress was mostly organized by national organizations for psychotherapy, by clinical psychologists working in hospitals, and by civic and nonprofit organizations. Many call centers were set up to provide immediate help for people experiencing distress, anxiety, and fear. Similar to other countries (Greenberg, Docherty, Gnanapragasam, \& Wessely, 
2020; Kang et al., 2020; Shah, Chaudhari, Kamrai, Lail, \& Patel, 2020), health care professionals face extreme psychological distress due to the recent crises.

\section{Conclusions}

The present study contributes to a better understanding of the variety of fears and traumatic emotional responses that are accompanying the outbreak of the COVID19 pandemic. Schimmenti, Billieux, and Starcevic (2020) provided preliminary theoretical categories of fear experienced during the COVID-19 pandemic: fear of/for the body, fear of/for significant others, fear of knowing/not knowing, and fear of taking action/inaction. However, this classification was not based on any empirical findings. The empirical evidence presented in the present study redefines this preliminary classification and shows the most frequent categories of fear that emerged as responses to the COVID-19 pandemic to be: (a) fear of the negative impact on household finances, (b) fear of the negative impact on the household finances of significant others, (c) fear of the unavailability of health care, and (d) fear of an insufficient food supply.

Furthermore, the communication used by the Czech mass media during the outbreak of the COVID-19 epidemic is a representative example of a traumatizing form of media communication during an epidemic. The anxious emotional tone of the messages and the presentation of selectively chosen "bad ending stories" contributed to the psychological traumatization of the Czech population during the COVID-19 outbreak. This form of communication was motivated by an effort to reach the broadest audience possible. The behavior of the Czech media demonstrates the highly sensitive nature of media communication during times of unprecedented crises and the key role of journalists and media officials in influencing the well-being of the general public. In this regard, Horesh and Brown (2020) suggested that the governments should provide clear guidelines and talking points for the media to use when speaking to a very anxious and potentially traumatized public. Future studies should also discuss the augmented role of ethics in media communication during times of unprecedented crises like the COVID-19 pandemic.

\section{References}

Ahorsu, D. K., Lin, C. Y., Imani, V., Saffari, M., Griffiths, M. D., \& Pakpour, A. H. (2020). The Fear of COVID-19 Scale: Development and initial validation. International Journal of Mental Health and Addiction. https://doi.org/10.1007/s11469-020-00270-8

Asmundson, G. J., \& Taylor, S. (2020). How health anxiety influences responses to viral outbreaks like COVID-19: What all decision-makers, health authorities, and health care professionals need to know. Journal of Anxiety Disorders, 71, 102211. https://doi.org/10.1016/j.janxdis.2020.102211

Behavio Labs. (2020, April). Coronavirus: A quick survey in the Czech Republic. https://atlascechu.cz/results/e3_strach 
Cao, W., Fang, Z., Hou, G., Han, M., Xu, X., Dong, J., \& Zheng, J. (2020). The psychological impact of the COVID-19 epidemic on college students in China. Psychiatry Research, 112934.

https://doi.org/10.1016/j.psychres.2020.112934

Dong, M., \& Zheng, J. (2020). Letter to the editor: Headline stress disorder caused by Netnews during the outbreak of COVID-19. Health Expectations: An International Journal of Public Participation in Health Care and Health Policy, 23(2), 259. https://doi.org/10.1111/hex.13055

European National Panels. (2020, April). National Pandemic Alarm: A representative survey monitoring public opinion, emotions and experience with novelty Corona virus spread in five Central European countries. https://www.nationalpandemicalarm.eu/main-en.html

Greenberg, N., Docherty, M., Gnanapragasam, S., \& Wessely, S. (2020). Managing mental health challenges faced by healthcare workers during covid-19 pandemic. BMJ, 368. https://doi.org/10.1136/bmj.m1211

Harper, C. A., Satchell, L. P., Fido, D., \& Latzman, R. D. (2020). Functional fear predicts public health compliance in the COVID-19 pandemic. International Journal of Mental Health and Addiction. https://doi.org/10.1007/s11469-02000281-5

Horesh, D., \& Brown, A. D. (2020). Traumatic stress in the age of COVID-19: A call to close critical gaps and adapt to new realities. Psychological Trauma: Theory, Research, Practice, and Policy, 12(4), 331-335. http://dx.doi.org/10.1037/tra0000592

Kang, L., Li, Y., Hu, S., Chen, M., Yang, C., Yang, B. X., ... \& Chen, J. (2020). The mental health of medical workers in Wuhan, China dealing with the 2019 novel coronavirus. The Lancet Psychiatry, 7(3), e14. https://doi.org/10.1016/S22150366(20)30047-X

Kisely, S., Warren, N., McMahon, L., Dalais, C., Henry, I., \& Siskind, D. (2020). Occurrence, prevention, and management of the psychological effects of emerging virus outbreaks on healthcare workers: Rapid review and metaanalysis. BMJ: British Medical Journal, 369. https://doi.org/10.1136/bmj.m1642

Liang, L., Ren, H., Cao, R., Hu, Y., Qin, Z., Li, C., \& Mei, S. (2020). The effect of COVID-19 on youth mental health. Psychiatric Quarterly, 1-12. https://doi.org/10.1007/s11126-020-09744-3

Lei, L., Huang, X., Zhang, S., Yang, J., Yang, L., \& Xu, M. (2020). Comparison of prevalence and associated factors of anxiety and depression among people affected by versus people unaffected by quarantine during the COVID-19 epidemic in Southwestern China. Medical Science Monitor: International Medical Journal of Experimental and Clinical Research, 26, e924609-1. https://doi.org/10.12659/MSM.924609

Roehr, S., Müller, F., Jung, F., Apfelbacher, C., Seidler, A., \& Riedel-Heller, S. G. (2020). Psychosocial impact of quarantine measures during serious Coronavirus outbreaks: A rapid review. Psychiatrische Praxis, 47(4), 179-189. https://doi.org/10.1055/a-1159-5562 
Schimmenti, A., Billieux, J., \& Starcevic, V. (2020). The four horsemen of fear: An integrated model of understanding fear experiences during the COVID-19 pandemic. Clinical Neuropsychiatry, 17(2), 41-45. https://doi.org/10.36131/CN20200202

Seznam.cz. (2020, April). The daily development of the reproduction number (R0). https://www.seznamzpravy.cz/sekce/koronavirus-stopcovid

Shah, K., Chaudhari, G., Kamrai, D., Lail, A., \& Patel, R. S. (2020). How essential is to focus on physician's health and burnout in Coronavirus (COVID-19) pandemic?. Cureus, 12(4), e7538. https://doi.org/10.7759/cureus.7538

Soraci, P., Ferrari, A., Abbiati, F. A., Del Fante, E., De Pace, R., Urso, A., \& Griffiths, M. D. (2020). Validation and psychometric evaluation of the Italian version of the Fear of COVID-19 Scale. International Journal of Mental Health and Addiction, 1-10. https://doi.org/10.1007/s11469-020-00277-1

STEM. (2020, April). Perception of the situation and precautions around the COVID19 coronavirus pandemic. https://www.stem.cz/vnimani-situace-a-opatrenikolem-pandemie-koronaviru-covid-19/

Torales, J., O'Higgins, M., Castaldelli-Maia, J. M., \& Ventriglio, A. (2020). The outbreak of COVID-19 coronavirus and its impact on global mental health. International Journal of Social Psychiatry, 0020764020915212. https://doi.org/10.1177/0020764020915212

Usher, K., Durkin, J., \& Bhullar, N. (2020). The COVID-19 pandemic and mental health impacts. International Journal of Mental Health Nursing. https://doi.org/10.1111/inm.12726

Wang, C., Pan, R., Wan, X., Tan, Y., Xu, L., Ho, C. S., \& Ho, R. C. (2020). Immediate psychological responses and associated factors during the initial stage of the 2019 coronavirus disease (COVID-19) epidemic among the general population in China. International Journal of Environmental Research and Public Health, 17(5), 1729. https://doi.org/10.3390/ijerph17051729

Zhou, S. J., Zhang, L. G., Wang, L. L., Guo, Z. C., Wang, J. Q., Chen, J. C., ... \& Chen, J. X. (2020). Prevalence and socio-demographic correlates of psychological health problems in Chinese adolescents during the outbreak of COVID-19. European Child \& Adolescent Psychiatry. https://doi.org/10.1007/s00787-020-01541-4 